\title{
RECHARGE AREA OF SELECTED LARGE SPRINGS IN THE OZARKS
}

\author{
James W. Duley \\ Missouri Geological Survey, 111 Fairgrounds Road, Rolla, MO, 65401, USA, bill.duley@dnr.mo.gov
}

Cecil Boswell

Missouri Geological Survey, 111 Fairgrounds Road, Rolla, MO, 65401, USA, cecil.boswell@dnr.mo.gov

Jerry Prewett

Missouri Geological Survey, 111 Fairgrounds Road, Rolla, MO, 65401, USA, jerry.prewett@dnr.mo.gov

\begin{abstract}
Ongoing work by the Missouri Geological Survey (MGS) is refining the known recharge areas of a number of major springs in the Ozarks. Among the springs being investigated are: Mammoth Spring (Fulton County, Arkansas), and the following Missouri springs: Greer Spring (Oregon County), Blue Spring (Ozark County), Blue/Morgan Spring Complex (Oregon County), Boze Mill Spring (Oregon County), two different Big Springs (Carter and Douglas County) and Rainbow/North Fork/ Hodgson Mill Spring Complex (Ozark County). Previously unpublished findings of the MGS and USGS are also being used to better define recharge areas of Greer Spring, Big Spring (Carter County), Blue/Morgan Spring Complex, and the Rainbow/ North Fork/Hodgson Mill Complex (Ozark County).
\end{abstract}

MGS is applying a graphical method of data analysis using spectrofluorometric scan results. Comparing the dye peak intensity to the intensity of the valley preceding the peak yields a ratio that can be used to standardize and quantify water traces. This method can be applied to current and some legacy traces with comparable results.

In some cases, past tracer injection sites were utilized in attempts to replicate older traces from those locations. The data clearly show that there is value in applying spectrofluorometric dye detection techniques in attempting to replicate older traces. Some repeat injections and subsequent monitoring confirmed earlier traces. Other replication efforts revealed multiple recovery points that were undetected by the legacy traces, thus expanding known recharge areas. Still other replication efforts indicate that some older traces are not repeatable. The effect of the replication efforts significantly changes the logical interpretation of a number of recharge area boundaries.

Among the findings of the overall study to date: Mammoth Spring and Greer Spring share a portion of their recharge, with the majority of Greer Spring's flow ap- parently passing under a gaining segment of the 11 Point River, ultimately emerging more than four kilometers to the southeast. This and other findings raise questions about how hydrology in the study area may be controlled by deep-seated mechanisms such as basal faulting and jointing. Research and understanding would be improved by 1:24,000 scale geologic mapping and increased geophysical study of the entire area.

\section{Introduction}

In the latter half of the 20th century, the US Forest Service and the National Park Service began serious efforts to define the recharge areas of some of the largest springs in the Ozarks of south central Missouri using water tracing techniques. The scientific community is indebted to committed professional investigators such as Tom Aley, Everett Chaney, Mickey Fletcher, and Chuck Tryon who contributed to the work in this region. In addition, Jim Vandike as a graduate student conducted numerous traces in the North Fork watershed.

These water tracing efforts were groundbreaking since there had been no previous organized effort to determine recharge areas of these springs that are among the largest in the nation. Techniques used were state-of-the-art for US investigators at the time. Most of the work employed activated carbon packets to collect fluorescein dye. Packets were anchored in springs and other monitoring points, and replaced on a routine basis. The removed packets were then washed in water and dye eluted via a basic solution. Dye detection was routinely conducted by visual analysis of the eluate from each packet.

While most of the older traces still seem to fit into existing paradigms with respect to the recharge areas of the major springs, questions have arisen about the accuracy of some. Beginning in 2013, the Missouri Geological Survey (MGS) conducted a number of dye traces with the goal of better defining the recharge areas of Big Spring in Carter County, Missouri, Greer Spring, 
Blue Spring and Morgan Spring in Oregon County, Missouri, Rainbow Spring, North Fork Spring, Hodgson Mill Spring, and Blue Spring in Ozark County, Missouri and Mammoth Spring in Fulton County, Arkansas. Most of this work was completed using techniques that were similar to those used decades ago: carbon packets as dye collectors, eluted in a basic alcohol solution. The biggest changes follow:

- Multiple tracers were used with eluate analyzed with a fluorescence spectrometer at the MGS Water Tracing Laboratory.

- Additional monitoring points were used based on past work and new findings.

- Monitoring was more extensive with multiple packets collected to characterize background conditions and to obtain more complete dye recovery curves.

- Recovery curves were plotted using Peak Valley Ratios (PVR) to compare relative dye intensities.

Fluorescence spectrometry methods remove some of the inherent subjectivity of visual detection and quantification methods and allow the use of multiple fluorescent tracers. They also improve detection limits. Some timeof-travel information was obtained with a fluorometer and associated logger placed in Mammoth Spring.

It should be noted that the intent of the current study is not to undermine the pioneering work that was completed decades ago by a number of forward-thinking individuals and organizations. Our goal is improvement of the data-base by adding to, enhancing, and refining the work of those pioneers.

\section{Geohydrology of the Study Area}

Detailed geologic mapping is not available for most of the study area. Reconnaissance quality mapping shows that the bedrock near the surface is nearly horizontal, fractured and solutioned dolostone of the Ordovician age Cotter, Jefferson City, Roubidoux and Gasconade formations with some fractured sandstone of the Roubidoux Formation. In many areas the Jefferson City and Cotter formations display relatively low permeability, but locally they are prone to extremely deep weathering with attendant sinkholes, and losing streams. The Roubidoux Formation is typically fractured and permeable and host to karst features such as sinkholes and losing streams. The upper part of the Gasconade Formation is one of the prime strata for cave development in the central Ozark region. While the Cambrian aged Eminence Formation (also largely comprised of dolostone) is not well exposed in the study area, deeper groundwater circulation does move through voids in this unit.
Past tracing efforts (Kleeschulte and Duley, 1985) have shown that geologic structures can be crucial in directing flow in karst aquifers in Missouri. The limited geologic mapping that has been done in the study area has shown that faulting is common with some notable structures discernible even on reconnaissance mapping (Figure 1). Work by Lowell et. al. (2010) and Weary et. al. (2014) implies a number of sizable structures apparently interpolated from remote imagery. But without detailed geologic mapping, the impact of these structures can only be surmised.

The Ozarks of southern Missouri and northern Arkansas contain some of the best examples of karst features observed anywhere in the US. The big spring region in south-central Missouri contains the recharge areas of a number of first order magnitude springs including the three largest in the Ozarks: Big Spring (with a mean discharge of $12.7 \mathrm{~m}^{3} / \mathrm{s}$ in Carter County, Missouri) Mammoth Spring (with a mean discharge of $9.9 \mathrm{~m}^{3} / \mathrm{s}$ and located just south of the Missouri state line in Fulton County, Arkansas) and Greer Spring (with a mean discharge of $9.8 \mathrm{~m}^{3} / \mathrm{s}$ in Oregon County, Missouri). In addition, water tracing has shown that Rainbow Spring, North Fork Spring and Hodgson Mill Spring are all part of a single complex. While discharge information is limited for the springs in the Rainbow/North Fork/Hodgson Mill complex, the combined mean discharge is about 6 $\mathrm{m}^{3} / \mathrm{s}$. Thus the complex would the considered to be the fourth largest system in the Ozarks.

\section{Prioritizing Traces for Replication}

While many historical traces completed in the karst region of south central Missouri and north central Arkansas agree with current interpretations of recharge areas, it should be noted that recharge area boundaries shown in recent publications (Mugel et al, 2009; Imes et al, 2007) are largely based on traces completed in the latter part of the 20th century with some seepage run and potentiometric data for support. Prior to the current study, few of the traces had been replicated with fluorescence spectrometry methods. As a result some of the older traces have come under scrutiny for a variety of reasons.

In order to prioritize traces for replication, MGS staff considered a number of issues. One overriding concern was selection of traces where a reasonable monitoring effort could produce the most valuable data in a relatively short period of time due to budget constraints. The following factors were considered as additional reasons to attempt to replicate traces in the study area:

- A small number of traces have been discounted in subsequent studies. 


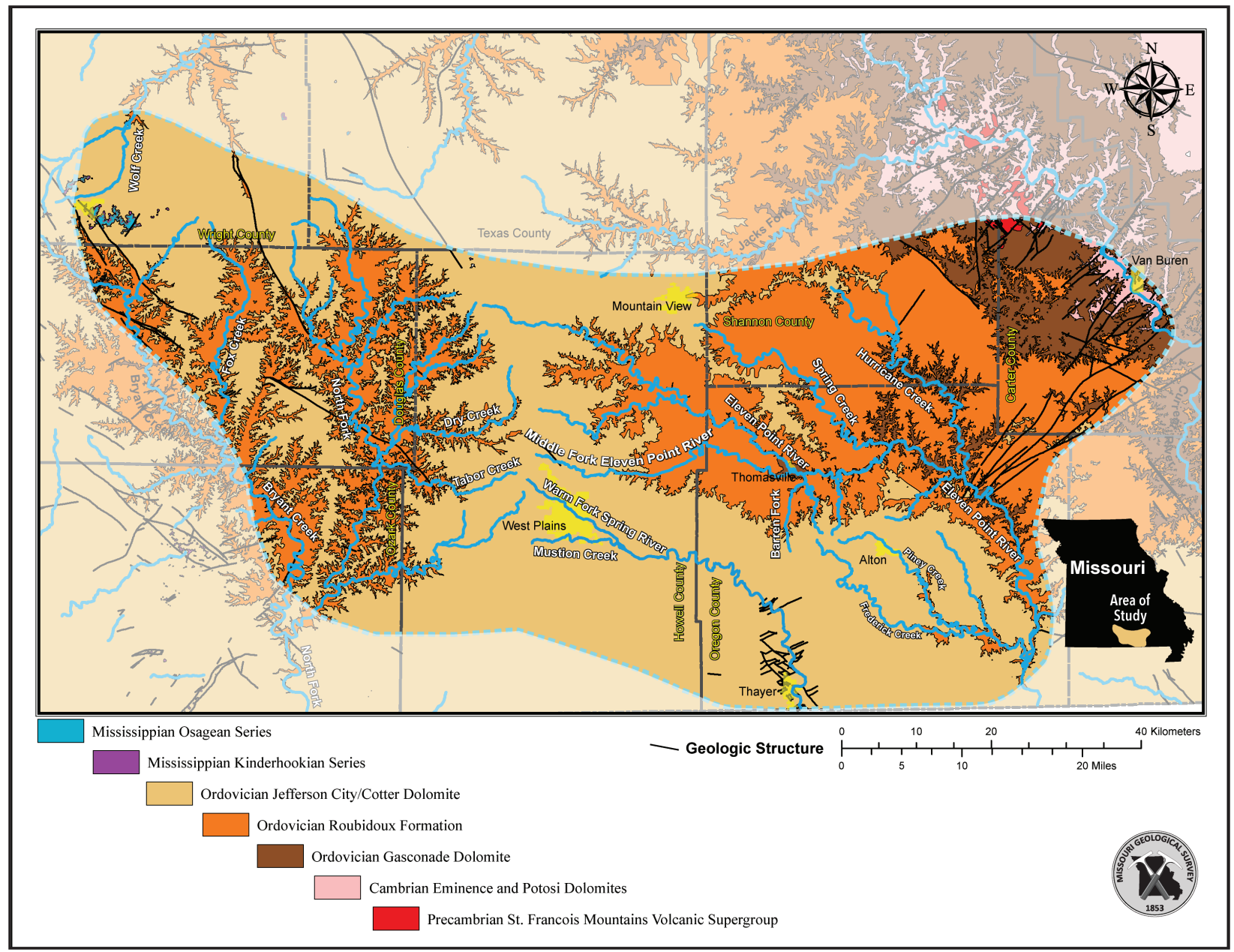

Figure 1. Geologic Map of the Study Area.

- A limited number of traces appear to conflict with available potentiometric data.

- Essentially all of the older traces in the study area were completed with subjective (visual) detection methods.

- Several traces were found to have questionable timing of injections causing a possible overlap with other injections.

- Several traces had a single reported recovery, or no detailed recovery information at all.

- Traces near the boundary of the recharge area in question were replicated in some instances because of the relative importance placed upon them with respect to planning and impact on future studies.

- Traces with inadequate, or no other monitoring points recorded were considered as needing replication because of the uncertainty with respect to other potential recoveries related to the original injection.

\section{Current MGS Techniques for Dye Collection and Analysis using Carbon Packets}

The standard protocol used by MGS in recent years involves use of activated coconut charcoal (6 to 12 mesh) to collect fluorescent tracers in the field. Charcoal is placed in packets constructed of nylon window screen. The packets are then secured in the water to be monitored. They are replaced on schedules varying from weekly to monthly and analyzed in the MGS Water Tracing Laboratory using fluorescence spectrometric techniques. Background packets are normally collected and analyzed for periods ranging from weeks to months prior to dye injection.

Charcoal packets are washed and placed in 100 milliliter cups with screw top lids. The dyes are eluted from the charcoal using a solution of 5\% ammonium hydroxide in ethyl alcohol for one hour. Eluate is pipetted from the charcoal and placed in disposable polystyrene cuvettes 
produced specifically for fluorescence studies. Currently analysis is completed using a Hitachi F7000 synchronously scanning fluorescence spectrophotometer. Analysis involves synchronously scanning the eluate with a seventeen (17) nanometer (nm) separation between excitation and emission using procedures similar to those developed by Duley (1986). Using current protocol the Hitachi measures and records fluorescence intensity from $450 \mathrm{~nm}$ to $620 \mathrm{~nm}$ excitation ( $467 \mathrm{~nm}$ to $637 \mathrm{~nm}$ emission). Results are plotted on the excitation wavelength axis.

Fluorescent dyes are typically indicated by the presence of background-modified normal (Gaussian) peaks. Dye peaks are superimposed on background fluorescence, with the greatest background impact occurring at lower wavelengths. Fluorescein is indicated by a well-defined peak between $495 \mathrm{~nm}$ and $505 \mathrm{~nm}$. Eosine is indicated by the presence of a well-defined peak occurring between $521 \mathrm{~nm}$ and $525 \mathrm{~nm}$. Rhodamine WT is indicated by a well-defined peak occurring between $544 \mathrm{~nm}$ and $553 \mathrm{~nm}$.

When more than one tracer is present in the same eluate, their fluorescent spectra overlap somewhat. If one tracer is found at a particularly high concentration, detection of other tracers may be problematic. For this reason MGS staff often staggers dye injections to allow the typically large pulse of one tracer to dissipate prior to recovery of a second or third tracer. MGS staff have also developed a simple chemical method to lower the $\mathrm{pH}$ of samples to a level that lowers fluorescein fluorescence so that it does not overshadow eosine or Rhodamine WT. It should be noted that the peak wavelengths of both eosine and Rhodamine WT increase (up to several nanometers above normal) when this method is used.

In order to compare data from a broad array of analytical instruments used over the last thirty years, MGS developed a simple method to normalize spectral data. When possible, instrumental dye peak height value (as measured from zero on the $\mathrm{X}$-axis in any instrumental unit) is divided by the value of the lowest intensity of the spectral valley that occurs between the fluorescent background maxima and the dye in question (Figure 2).

This peak to valley ratio (PVR) gives the investigator a quick and simple way to compare data from a variety of instruments ranging from those with analog printouts to digital data. By definition the PVR must be greater than 1.0 to indicate the presence of dye. If there is no dye peak, there is no valley and the PVR is assumed to be 1.0. MGS interpretations of different PVRs are shown below:

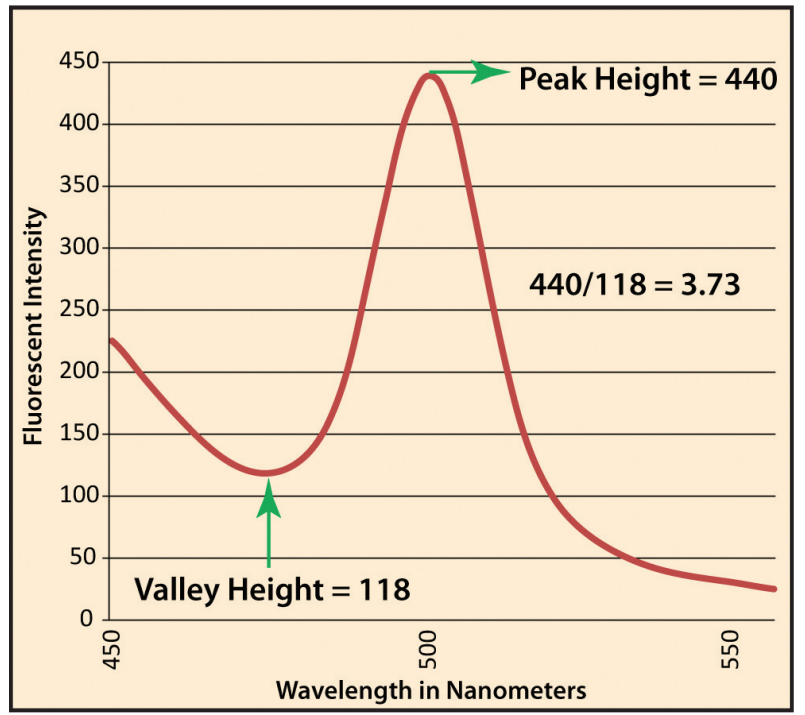

Figure 2. Peak Valley Ratio Determination Example.

- A PVR of 1 is indicative of background conditions since, by definition, there is no dye peak.

- A PVR of 1 to 2 is a small dye recovery. This level in background packets is indicative of sewage or another limited source of tracer.

- When the PVR is greater than 2 and up to 5 a moderate dye recovery, normally from a current injection, is indicated.

- A PVR greater than 5 and up to 10 is a large dye recovery that indicates a strong connection to a current injection.

- A PVR greater than 10 is a very large recovery that indicates a strong and direct connection to a current injection.

\section{Results and Recommendations}

A combination of new injection points and repeat injections at locations used for legacy traces has helped to create a clearer picture of the recharge areas of some of the springs in question (Figure 3 and Table 1).

Replication efforts of older traces show the value of newer techniques. A limited number of repetitions show that some past investigators may have reported positive recoveries of dye erroneously. They also show that some actual resurgence points were not monitored or tracers were not detected due to limitations of the older detection methodologies. In addition, injection overlap may have been a serious problem in some traces.

While geologic conditions such as degree of bedrock fracturing, degree of weathering, and location of faults, 


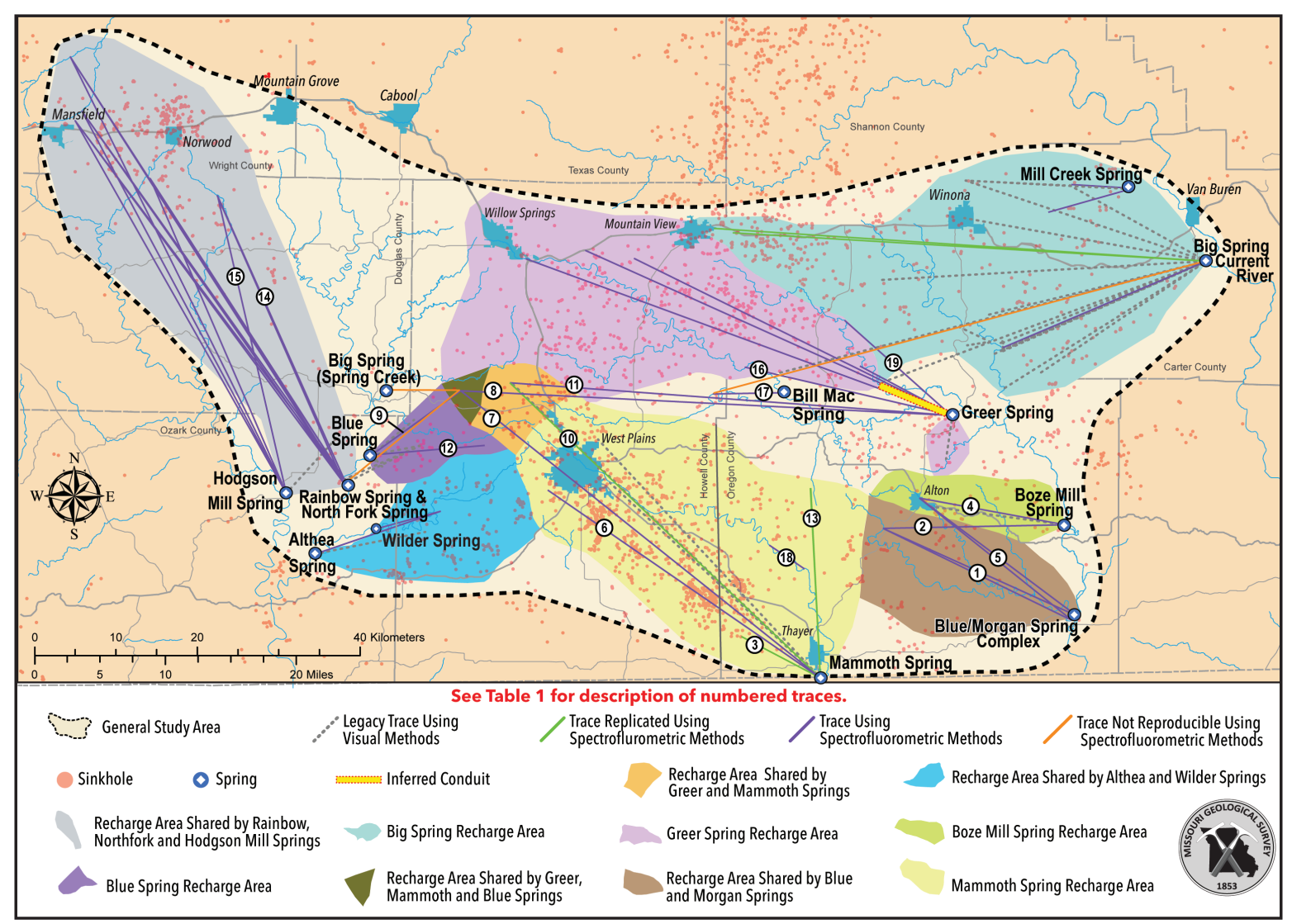

Figure 3. Recharge Areas of Selected Springs in the Southern Ozarks. Older dye traces referenced in this figure are discussed in Aley (1972; 1975), Vandike (1979), and Aley and Aley (1987). Replication attempts are discussed in Imes and Frederick (2002)and Imes et al. (2007). Results of more recent traces are discussed in Gilman et al. (2008).

folds and discontinuous low permeability beds are the prime factors that determine how groundwater moves in this region, insufficient data are available to predict groundwater recharge areas using existing geologic mapping alone. Thus recharge area boundaries on Figure 3 are approximate and were drawn based on the following factors (listed in order of importance):

1. Sound and repeatable dye traces

2. Potentiometric data from groundwater and surface water

3. Losing/gaining stream determinations

4. Water quality

Data gathered during this study shows that the recharge area of the Blue Spring/Morgan Spring Complex extends to the west and south of the city of Alton, likely encompassing most of the drainage of Frederick Creek (excluding the upper reaches of Piney Creek tributary). Piney Creek, which flows through the city of Alton, is largely in the recharge area of Boze Mill Spring. It is likely that during wetter periods, surface flow carries some water into the lower reaches of Piney Creek and/or Frederick Creek basins where it is subsequently lost to the subsurface and resurfaces at the Blue Spring/Morgan Spring Complex. This connection is minor as it is transitory in nature with little actual water movement between the upper reaches of Piney Creek and the Blue Spring/ Morgan Spring Complex.

New traces in the recharge area of Mammoth Spring show that some early traces are accurate or at least partially so. However, new traces from replicated injection points show that a significant portion of the northern end of the Mammoth Spring recharge area is shared with Greer Spring and Blue Spring on the North Fork. This extends the known recharge area of both Mammoth Spring (to the northeast) and Greer Spring (to the southwest). Significant questions still remain about the boundary between Greer Spring on the north and Mammoth Spring on the south. 


\begin{tabular}{|c|c|c|c|c|c|c|c|c|c|}
\hline $\begin{array}{c}\text { Trace } \\
\#\end{array}$ & From & To & $\begin{array}{c}\text { Dye* } \\
\text { (Amount) }\end{array}$ & $\begin{array}{c}\text { Distance } \\
\text { in } \mathrm{Km}\end{array}$ & $\begin{array}{l}\text { Injection } \\
\text { Date }\end{array}$ & $\begin{array}{c}\text { First } \\
\text { Recovery } \\
\text { Velocity } \\
(\mathrm{m} / \mathrm{hr})\end{array}$ & $\begin{array}{c}\text { Peak } \\
\text { Recovery } \\
\text { Velocity } \\
(\mathrm{m} / \mathrm{hr}\end{array}$ & $\begin{array}{l}\text { Peak } \\
\text { PVR }\end{array}$ & Remarks \\
\hline 1 & Frederick Creek & $\begin{array}{l}\text { Blue/Morgan } \\
\text { Complex }\end{array}$ & $\mathrm{F} 1(4.5 \mathrm{~kg})$ & 25.9 & $8 / 27 / 2013$ & $36-49$ & $30-36$ & 33.9 & Principle dye recovery point. \\
\hline 2 & Frederick Creek & Boze Mill Spring & $\mathrm{Fl}(4.5 \mathrm{~kg})$ & 22.4 & $8 / 27 / 2013$ & $27-31$ & $22-27$ & 2.1 & Secondary dye recovery point. \\
\hline 3 & Grand Gulf & Mammoth Spring & RWT (11.4 l) & 11.0 & $10 / 9 / 2013$ & 88 & 49 & 15.9 & $\begin{array}{l}\text { Only dye recovery point. Con- } \\
\text { firms earlier trace. }\end{array}$ \\
\hline 4 & $\begin{array}{c}\text { Piney Creek in } \\
\text { Alton }\end{array}$ & Boze Mill Spring & RWT (11.4 l) & 18.2 & $12 / 4 / 2013$ & $54-96$ & $40-54$ & 133.2 & Principle dye recovery point. \\
\hline 5 & $\begin{array}{c}\text { Piney Creek in } \\
\text { Alton } \\
\end{array}$ & $\begin{array}{c}\text { Blue/Morgan } \\
\text { Complex }\end{array}$ & RWT (11.4 1) & 24.1 & $12 / 4 / 2013$ & $29-39$ & $25-29$ & 1.3 & Secondary dye recovery point. \\
\hline 6 & Mustion Creek & Mammoth Spring & $\mathrm{Fl}(4.5 \mathrm{~kg})$ & 40.7 & $2 / 14 / 2014$ & $85-153$ & $68-85$ & 217.3 & Only dye recovery point. \\
\hline 7 & $\begin{array}{l}\text { Rattlesnake } \\
\text { Spring }\end{array}$ & Mammoth Spring & Eos $(4 \mathrm{~kg})$ & 56.6 & $2 / 26 / 2014$ & $81-117$ & $69-81$ & 9.2 & Did not agree with legacy traces. \\
\hline 8 & $\begin{array}{l}\text { Rattlesnake } \\
\text { Spring }\end{array}$ & Greer Spring & Eos $(4 \mathrm{~kg})$ & 60.5 & $2 / 26 / 2014$ & $87-90$ & $74-87$ & 13.9 & Did not agree with legacy traces. \\
\hline 9 & $\begin{array}{l}\text { Rattlesnake } \\
\text { Spring }\end{array}$ & $\begin{array}{l}\text { Blue Spring N. } \\
\text { Fork } \\
\end{array}$ & Eos (4 kg) & 13.5 & $2 / 26 / 2014$ & $12-14$ & 7 & 4.2 & Did not agree with legacy traces. \\
\hline 10 & $\begin{array}{c}\text { Dry Creek near } \\
\text { Pomona }\end{array}$ & Mammoth Spring & RWT (11.4 1) & 52.7 & $3 / 26 / 2014$ & $81-110$ & $81-110$ & 8.4 & $\begin{array}{l}\text { Recovery point that replicates } \\
\text { legacy trace. }\end{array}$ \\
\hline 11 & $\begin{array}{c}\text { Dry Creek near } \\
\text { Pomona }\end{array}$ & Greer Spring & RWT (11.4 1) & 54.6 & $3 / 26 / 2014$ & $84-114$ & $81-114$ & 10.2 & $\begin{array}{l}\text { Additional recovery found in } \\
\text { replication attempt. }\end{array}$ \\
\hline 12 & $\begin{array}{c}\text { Upper Tabor } \\
\text { Creek }\end{array}$ & $\begin{array}{l}\text { Blue Spring N. } \\
\text { Fork }\end{array}$ & $\mathrm{F} 1(2.2 \mathrm{~kg})$ & 13.9 & $6 / 17 / 2014$ & $28-85$ & $21-28$ & 246.9 & Only dye recovery point. \\
\hline 13 & $\begin{array}{c}\text { Granny Meyers } \\
\text { Spring }\end{array}$ & Mammoth Spring & Eos $(2.2 \mathrm{~kg})$ & 23.4 & $7 / 16 / 2014$ & $36-48$ & $29-36$ & 29.9 & $\begin{array}{l}\text { Only dye recovery point. Con- } \\
\text { firms legacy trace. }\end{array}$ \\
\hline 14 & $\begin{array}{l}\text { Upper Fox } \\
\text { Creek }\end{array}$ & $\begin{array}{l}\text { Rainbow/North- } \\
\text { Fork Compl. }\end{array}$ & Eos $(2.2 \mathrm{~kg})$ & 38.2 & $8 / 19 / 2014$ & $116-206$ & $78-116$ & 98.7 & $\begin{array}{l}\text { Recovery point closely tied to } \\
\text { Hodgson Mill. }\end{array}$ \\
\hline 15 & $\begin{array}{c}\text { Upper Fox } \\
\text { Creek }\end{array}$ & $\begin{array}{l}\text { Hodgson Mill } \\
\text { Spring } \\
\end{array}$ & Eos $(2.2 \mathrm{~kg})$ & 37.5 & $8 / 19 / 2014$ & $122-198$ & $75-112$ & 88.3 & $\begin{array}{c}\text { Recovery point tied to } \\
\text { Rainbow/N. Fork Comp. }\end{array}$ \\
\hline 16 & $\begin{array}{l}11 \text { Point at Lost } \\
\text { Hill }\end{array}$ & Greer Spring & $\operatorname{Eos}(2.2 \mathrm{~kg})$ & 26.1 & $10 / 28 / 2014$ & $69-186$ & $69-186$ & 18.2 & Only dye recovery point. \\
\hline 17 & $\begin{array}{c}\text { Middle Fork } 11 \\
\text { Point }\end{array}$ & Bill Mac Spring & RWT (11.4 1) & 8.4 & $12 / 11 / 2014$ & $14-19$ & $9-11$ & 5.0 & Did not agree with legacy traces. \\
\hline 18 & $\begin{array}{c}\text { Warm Fork } \\
\text { Losing Stream }\end{array}$ & $\begin{array}{l}\text { Warm Fork } \\
\text { Spring }\end{array}$ & $\mathrm{Fl}(0.45 \mathrm{~kg})$ & 4.8 & $1 / 21 / 2015$ & $>32$ & $>32$ & 48.5 & Only dye recovery point \\
\hline 19 & $\begin{array}{c}\text { Cave Spring on } \\
\text { Spring Cr. }\end{array}$ & Greer Spring & $\mathrm{Fl}(2.2 \mathrm{~kg})$ & 17.7 & $1 / 21 / 2015$ & $26-37$ & $18-26$ & 7.5 & Only dye recovery point. \\
\hline
\end{tabular}

Table 1. Basic Information about Recent MGS Traces in the Study Area.

Data also show that, while Upper and Lower Greer Spring are clearly part of the same system, on one occasion, dye recovery at Upper Greer Spring was shown to lag behind the recovery at Lower Greer Spring, presumably due to the head differential and circuitous route for discharging water flowing to the surface at the higher cave outlet of Upper Greer. Yet another trace demonstrates that the Eleven Point River contributes recharge to both Greer Springs from the region about $8 \mathrm{~km}$ upstream of Thomasville. Figure 4 is a graphical depiction of this trace. The new information shows that much of Greer Spring's recharge travels beneath a gaining section of the 11 Point River, surfacing $4 \mathrm{~km}$ to the southeast.

One new trace was completed from an upper reach of Tabor Creek to Blue Spring on the North Fork which helps to define the boundary between the recharge areas of Blue, Greer and Mammoth springs.A new trace was completed during this study to the Rainbow/North Fork/Hodgson Mill Complex which extends the known recharge area to include upper Fox Creek. At least one legacy connection to the Complex completed using visual methods was discounted by an attempt to replicate the old trace. It is recommended that additional tracing be conducted to determine what amount (if any) of the recharge area of the Complex is located east of the North Fork River. It is also recommended that additional work be done to better define the relationship between Hodgson Mill Spring and the main resurgences of the Complex at Rainbow and North Fork Spring.

As a final recommendation, the entire region would benefit from detailed geologic mapping. The limited amount of available detailed mapping gives clues helpful in predicting groundwater flow direction and resur- 


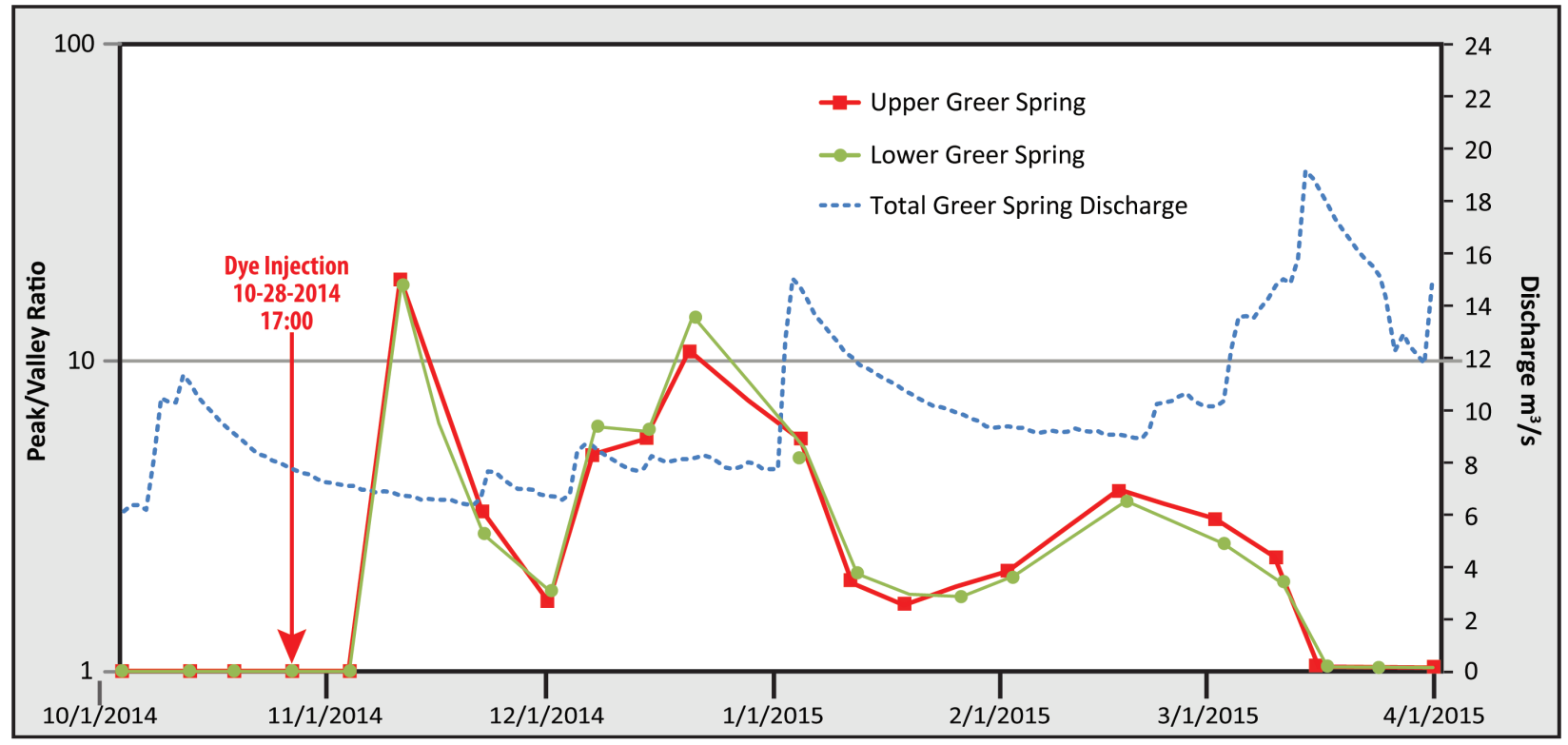

Figure 4. Dye Recovery Curves for Upper and Lower Greer Spring during the Lost Hill Trace. Peak valley Rations are plotted on the dates that carbon packets were collected.

gence points but much more work is required to get a more complete picture of bedrock influences on the karst system. Geologic mapping at a scale of 1:24,000 is in dire need to show the location of structures involved in directing groundwater movement. This mapping would benefit those dealing with water supply, waste disposal, and watershed protection issues alike.

\section{References}

Aley TJ. 1972. Groundwater Contamination from Sinkhole Dumps. Caves and Karst 14 (3): 17-23.

Aley TJ. 1975. A Predictive Hydrologic Model for Evaluating the Effects of Land Use and Management of the Quantity and Quality of Water from Ozark Springs: Protem, Missouri. Ozark Underground Laboratory.

Aley TJ, Aley C. 1987. Groundwater Study, Ozark National Scenic Riverways: Volume 1. Protem, Missouri, Ozark Underground Laboratory.

Duley JW. 1986. Water Tracing using a Scanning Spectrofluorometer for Detection of Fluorescent Dyes. Proceedings of the Environmental Problems in Karst Terranes and their Solutions Conference, National Water Well Association: p. 389-406.

Gillman J, Crews R, Prewett J. 2008. Dye Tracing Animal Waste Effluent in the North Fork Basin, Southern Missouri. Sinkholes and the Engineering and Environmental Impacts of Karst. p. 467-476.

Imes JL, Plummer LN, Kleeschulte, MJ, Schumacher JG. 2007. Recharge Area, Base-Flow and Quick-
Flow Discharge Rates and Ages, and General Water Quality of Big Spring in Carter County, Missouri, 2000-04, USGS Scientific Investigations Report 2007-5049.

Imes JL, Fredrick BS. 2002. Using Dye-Tracing and Chemical Analysis to Determine Effects of a Wastewater Discharge to Jam Up Creek on Water Quality of Big Spring, Southeastern Missouri, 2001. USGS Fact Sheet 103-02.

Kleeschulte MJ, Duley JW. 1985.Geology, Water Movement and Sediment Characteristics of the Sugar, Romaine and Rock Creek Basins, Jefferson County, Missouri. Missouri Department of Natural Resources, Geology and Land Survey Division Open File Report OFR-85-30-EG.

Lowell GR, Harrison RW, Weary DJ, Orndorff RC, Repetski JC, Pierce HA. 2010. Rift-Related Volcanism and Karst Geohydrology of the Southern Ozark Dome.In: Evans KR, Aber JS, editors. From Precambrian Rift Volcanoes to the Mississippian Shelf Margin: Geological Field Excursions in the Ozark Mountains. Geological Society of America Field Guide 17. p. 99-158.

Mugel, DN, Richards JM, Schumacher JG. 2009. Geohydrologic Investigations and Landscape Characteristics of Areas Contributing Water to Springs, the Current River, and Jacks Fork, Ozark National Scenic Riverways, Missouri: US Geological Survey Scientific Investigations Report 2009-5138. 